Research Article

\title{
Effect of Experimental Parameters on the Formation of Hydrogels by Polyelectrolyte Complexation of Carboxymethylcellulose, Carboxymethyl Starch, and Alginic Acid with Chitosan
}

\author{
Elizabeth Henao Mejía, ${ }^{1}$ Héctor Contreras, ${ }^{2}$ Ezequiel Delgado, ${ }^{2}$ and Germán Quintana $\mathbb{D D}^{1}$ \\ ${ }^{1}$ Pulp and Paper Research Group, Faculty of Chemical Engineering, Universidad Pontificia Bolivariana, \\ Circular 1 \# 70-01 Medellín (Antioquia), Medellín, Colombia \\ ${ }^{2}$ Departamento de Madera, Celulosa y Papel (DMCyP), Universidad de Guadalajara, Km. 15.5, Carretera Guadalajara-Nogales, \\ Las Agujas, 45020 Zapopan, Jalisco, Mexico
}

Correspondence should be addressed to Germán Quintana; german.quintana@upb.edu.co

Received 27 November 2018; Accepted 13 February 2019; Published 7 March 2019

Academic Editor: Donald L. Feke

Copyright ( 2019 Elizabeth Henao Mejía et al. This is an open access article distributed under the Creative Commons Attribution License, which permits unrestricted use, distribution, and reproduction in any medium, provided the original work is properly cited.

\begin{abstract}
Differences in morphology, $\mathrm{pH}$, and electric charge of chitosan (CS) based hydrogels prepared by complexation with carboxymethylcellulose (CMC), carboxymethylated starch (CMS), and alginic acid (AA) at different polymers ratios and changing the order of addition were studied. CMC/CS and AA/CS hydrogels were amorphous and porous three-dimensional networks, with smaller pores at higher anionic polymer/CS ratios. Gelation time increased the agglomeration in the case of CMC/CS and $\mathrm{CMS} / \mathrm{CS}$ gels. CMC/CS gels showed negative zeta potential values around $-372 \mathrm{mV}$ to $-51 \mathrm{mV}$ and CMS/CS gels in the range of $-526 \mathrm{mV}$ and $-158 \mathrm{mV}$.
\end{abstract}

\section{Introduction}

Within the applications of biotechnology are the developments of therapeutic agents having applications in tissue engineering and controlled release of drugs. Ten of the twenty main world sales of medical treatments are biological products because the biotechnology offers advantages over traditional medicine such as the reduction of side effects and specific treatments [1]. Nanotechnology provides fundamental tools to control the release of these biological products and to design three-dimensional tissue scaffolds to support cell growth due to their similarity to the native extracellular matrix [2]. That is how the ability to control the properties and functionalities of hydrogel broadens the understanding of possible cell-matrix interactions at the nanometric scale, and comprehensive understanding of the processes involved in the self-assembly of hydrogels is essential for the development of relevant biotechnologycal applications [1].

Hydrogels are three-dimensional networks capable of absorbing large quantities of water or biological fluids; therefore, they attract interest in medicine [3]. Hydrogels are formed by chemical or physical crosslinking. Chemical crosslinking occurs by covalent bonds and physical crosslinking by hydrophobic interactions, hydrogen bonds, stereo complexes, and electrostatic or charge interactions [3]. Physical hydrogels have the advantage of responding to changes in the surrounding environment such as $\mathrm{pH}$, temperature, changes in ionic strength, or its state (swelling shrinkage) [4]. Noncovalent crosslinking allows the polymers to form a gel to be altered by the elimination of the weak links with changes of external factors such as $\mathrm{pH}$, ionic strength, and temperature. These changes could be used as triggers to deliver a drug in a specific site and can also help 
keep the effect of the drug over a period of time, days, or even weeks [5-7].

Within the development of therapeutic biomaterials is the development of hydrogels derived from biopolymers that are biocompatible with the human organism. Polysaccharides have been studied during the last years as raw materials in the encapsulation of drugs forming a mesh structure by charge interaction between anions and cations. Polysaccharides have peculiar properties such as good solubility in aqueous environments, high stability, null toxicity, biocompatibility, and biodegradability [8-10].

Several procedures for the manufacture of hydrogels by noncovalent crosslinking with carboxymethylcellulose, carboxymethylated starch, or alginic acid as anionic polymers with chitosan as the cationic polymer have been reported; each couple (polyanion/polycation) generates a hydrogel with different morphology [8, 11-13].

In hydrogel formation, both concentration of polymers and sequence of addition, among other factors, play important roles in the morphology and size of the hydrogel [14-16]. The aim of this research is to investigate the morphology, state aggregation, $\mathrm{pH}$, and electric charge of hydrogels obtained by polyanion (carboxylated starch and alginic acid) and polycation (chitosan) complexation, by varying the order of polymer addition and polymer-polymer ratios.

\section{Materials and Methods}

2.1. Materials. Carboxymethylcellulose (CMC) sodium salt, average molecular weight $(\mathrm{Mw}) \sim 250,000$ and 0.7 degree of substitution (CAS 9004-32-4), chitosan (CS), deacetylation $75-85 \%$, medium molecular weight (CAS 9012-76-4), and alginic acid (AA) of medium viscosity (CAS 9005-38-3) all were the products of Sigma-Aldrich. Carboxymethylated starch (CMS) was obtained from DFE Pharma at Foxhol, The Netherlands. The polymers were used as supplied.

\subsection{Sequence of Polymer Addition in the Ionotropic Gelation.} In order to evaluate the effect of changing the sequence of addition and concentration of the polymers, the morphology of hydrogels was examined. The concentration of CMC was fixed at $0.75 \% \mathrm{w} / \mathrm{v}$, while two CS preparations were employed ( 0.01 and $0.75 \%$ in acetic acid $1 \% \mathrm{v} / \mathrm{v})$, varying also the sequence of addition. At higher concentrations, CMC solutions were very viscous and the polymer was not completely solubilized.

2.2.1. CMC on CS. Approximately $10 \mathrm{~mL}$ of CMC solution was dropped through a needle $(21 \mathrm{G})$ from a plastic syringe into a beaker containing $10 \mathrm{~mL}$ of any CS solution $(0.01$ and $0.75 \%)$, under gentle stirring $(600 \mathrm{rpm})$ for 5 minutes at room temperature. Then, the mix was stirred for another 25 minutes, and the hydrogel was kept 12 hours at room temperature.
2.2.2. CS on CMC. Approximately $10 \mathrm{~mL}$ of any CS solution $(0.01$ and $0.75 \%)$ was dropped through a needle $(21 \mathrm{G})$ from a plastic syringe into a beaker containing $10 \mathrm{~mL}$ of CMC solution, under gentle stirring $(600 \mathrm{rpm})$ for 5 minutes at room temperature. Then, the mix was stirred for another 25 minutes, and the hydrogel was kept 12 hours at room temperature.

All the samples were centrifuged at $3300 \mathrm{rpm}$ for 30 minutes, and the precipitates were removed from the supernatants. The gel samples were then washed with water and separated again by centrifugation. The washing and centrifugation steps were repeated twice, and the samples were observed under a microscope (Leica DMREB, software LAS, version 7.1, Camera Leica DFC320).

2.3. Free Swelling Capacity. The free swelling capacity of hydrogels was determined as follows: the samples (gels) were dried until constant weight in an oven at $60^{\circ} \mathrm{C}$; then they were weighed and rehydrated in distilled water for 24 hours, and the excess water was removed with a dry paper, depositing the gel on it a few seconds before weighting. The weight difference was reported, and the gel samples were dried again. This procedure was applied to gels formed with $0.75 \%$ of both (CMC and CS), varying the sequence of addition.

2.4. Variation of Polymer-Polymer Ratio. CS concentration was fixed at $0.01 \% \mathrm{w} / \mathrm{v}$ (dissolved in acetic acid $1 \% \mathrm{v} / \mathrm{v}$ ) in order to avoid viscosity problems when mixed with anionic polymers at high concentrations. The concentration ranges chosen were as follows: CMC between $2 \%$ and $0.025 \% \mathrm{w} / \mathrm{v}$; CMS between 3.2 and $0.4 \% \mathrm{w} / \mathrm{v}$, and AA between 0.5 and $0.04 \% \mathrm{w} / \mathrm{v}$. Six different concentrations were used within each range. Polymer-polymer ratios are shown in Table 1. The gels were prepared as described before. The addition order CMC/CS was chosen due to the higher production of hydrogel compared to the sequence CS/CMC.

The hydrogel samples obtained at different polymerpolymer ratios were dried in an oven at $60^{\circ} \mathrm{C}$ until constant weight to calculate the yield as follows [17]:

$$
R=\left(\frac{W_{\mathrm{g}}}{W_{\mathrm{p}}}\right) \times 100,
$$

where $W_{\mathrm{g}}$ is the dry weight of the hydrogel and $W_{\mathrm{p}}$ is the weight of products used for the gel preparation.

2.5. Gel Morphology. To characterize the morphology of the wet gels at different polymer-polymer ratios, a drop of the sample was put on a slide with a drop of water to disperse the gel before the observation. Then, a coverslip was put upon, and the sample was observed under an optical microscope (Leica DMREB, software LAS, version 7.1, Camera Leica DFC320).

The dried gel morphology was observed from gel samples frozen with liquid nitrogen and then lyophilized. Samples were analyzed by using a scanning electron 
TABLE 1: Relation between anionic and cationic components for the different polymer systems.

\begin{tabular}{lcccccc}
\hline $\begin{array}{l}\text { Polymer-polymer } \\
\text { ratio }\end{array}$ & Ratio & Ratio & Ratio & Ratio & Ratio & Ratio \\
\hline CMC/CS & 1 & 2 & 3 & 4 & 5 & 6 \\
AA/CS & 200 & 75 & 32 & 21 & 2.7 & 2.5 \\
CMS/CS & 50 & 28 & 12 & 5.5 & 5 & 4 \\
\hline
\end{tabular}

microscope Hitachi TM-1000 (Hitachi High-Technologies Inc., Japan).

2.6. $\mathrm{pH}$ and Zeta Potential. The charge distribution (zeta potential) and $\mathrm{pH}$ of the gels were measured after a gelation time was established (between 20 and 24 hours after the preparation) to be associated with the polymer-polymer ratio used to prepare the hydrogels. The zeta potential was measured in a Zetasizer Nano ZS90 with DS170 cuvettes, using acetic acid as a solvent for chitosan and the hydrogels. Water was used as a solvent for the other polymer systems. The $\mathrm{pH}$ was measured using a benchtop $\mathrm{pH}$ meter.

2.7. FTIR Characterization of Gels. FTIR spectra of dried gel samples were recorded in a PerkinElmer FTIR spectrometer, model Spectrum GX with an attachment for attenuated total reflectance (ATR), and a diamond crystal. Spectra were taken between 4000 and $600 \mathrm{~cm}^{-1}$ with a resolution of $4.00 \mathrm{~cm}^{-1}$ and 16 scans.

2.8. Effects of Gelation Time on Hydrogel Morphology. In order to evaluate the effect produced by the time-to-reach the gelation on the morphology of hydrogels, the mix of polymers was agitated for 25 minutes and the complexation was stopped; at that time, the polymeric complex was centrifuged at $3300 \mathrm{rpm}$ for 30 minutes and the precipitate was removed from the supernatants. The gel samples were washed with water and separated again by centrifugation. Hydrogel surfaces were analyzed by zeta potential in a Zetasizer Nano ZS90 with DS170 cuvettes, and changes in the morphology were evaluated by using optical microscopy (Leica DMREB, software LAS, version 7.1, Camera Leica DFC320).

\section{Results and Discussion}

3.1. Effect of the Order of Polymer Addition on Gel Formation. CS and CMC form intermacromolecular complexes by the strong interaction between their functional groups, such as electrostatic interaction and hydrogen bonding [14]. Hydrogels were obtained for all studied sequences of addition, $\mathrm{CMC}$ on $\mathrm{CS}(\mathrm{CMC} / \mathrm{CS})$ and $\mathrm{CS}$ on $\mathrm{CMC}$ (CS/CMC) as reported by several authors $[14,16,18]$. It was observed that the order of polyelectrolyte mixing affected the hydrogels where, for example, CS/CMC hydrogels were formed at $\mathrm{pH}$ higher than that of CMC/CS $[14,19,20]$, and it produces differences in morphology and yield, similar to that reported by Fukuda [14].
At a CMC/CS ratio of 75:1 (low amount of CS), no precipitation or turbidity was observed when adding CS over $\mathrm{CMC}$; this behavior may be due to an excess of anionic charge $\left(\mathrm{COO}^{-}\right)$of $\mathrm{CMC}$ and a low $\mathrm{pH}$ that reduced the number of interactions with CS- $\mathrm{NH}_{3}{ }^{+}$groups. By changing the sequence of addition and dropping the $\mathrm{CMC}$ solution onto a diluted CS solution, the contact between polymers was improved and produced a cloudy suspension (Figure 1) yielding more gel particles [21]. These conditions rendered gel particles in the form of sponges (Figure 1(b)) having a pore size around 3 micrometers.

In the case of CMC added on CS at a ratio of 75, agglomeration could be observed under the microscope, while the addition of CS over CMS showed only a few visible particles (Figure 2).

Moreover, at a CMC/CS ratio of $1 / 1$, particles of the order of millimeters were observed. This gel showed more swelling than the hydrogel obtained by the addition of CS onto CMC (Figures 3(a) and 3(b)), thus indicating the importance of the order of addition of the polymers on gel morphology.

Complex and highly aggregated heterogeneous hydrogels were obtained by mixing polyelectrolytes of high or similar molecular weight. In this work, CMC and CS had an average molecular weight of $250 \mathrm{kDa}$. Molecular weight is a factor in the process of agglomeration. Among other factors (for instance, $\mathrm{pH}$ ), the higher the molecular weight, the more the ionic sites that would be available to interact [22].

The CMS/CS dried hydrogel prepared with a ratio of $1 / 1$ was a slim and translucent sponge that presented a network of particles of different sizes. The yield also changed with the sequence of addition. Thus, the hydrogel made adding CMC/ CS had a yield of $70.85 \%$ with a deviation of $1.67 \%$, and the inverse order of addition produced a yield close to $100 \%$ with a deviation of $1.86 \%$.

Hydrogels prepared at a ratio of $1 / 1$ had a swelling percent of $4325 \pm 46 \%$ when CMC was added onto CS, while the one formed with the inverse order had only $856 \pm 20 \%$ swelling. The swelling was calculated with the following equation [17]:

$$
S=\left(\frac{W_{\mathrm{a}}-W_{\mathrm{g}}}{W_{\mathrm{g}}}\right) \times 100,
$$

where $W_{\mathrm{g}}$ is the dry weight and $W_{\mathrm{a}}$ is the weight of the swollen gel.

3.2. Influence of Varying Polymer Ratio on Hydrogel Yield. Table 2 shows the hydrogel yields for each different combination of polymers. The CMC/CS hydrogels had a yield around $20 \%$ at almost all ratios; this result differs from those reported by Fukuda [14], in which the yield of CMC/CS hydrogels increased with the concentration of CS. The yield for AA/CS and CMS/CS hydrogels had a tendency to decrease with more CS added.

According to Gåserød et al. [23], the core of the hydrogel is formed by the polymer that is dropped on a solution of the polyelectrolyte of opposite charge; in the present work, the anionic polymer (AA) was dropped over the cationic CS, 

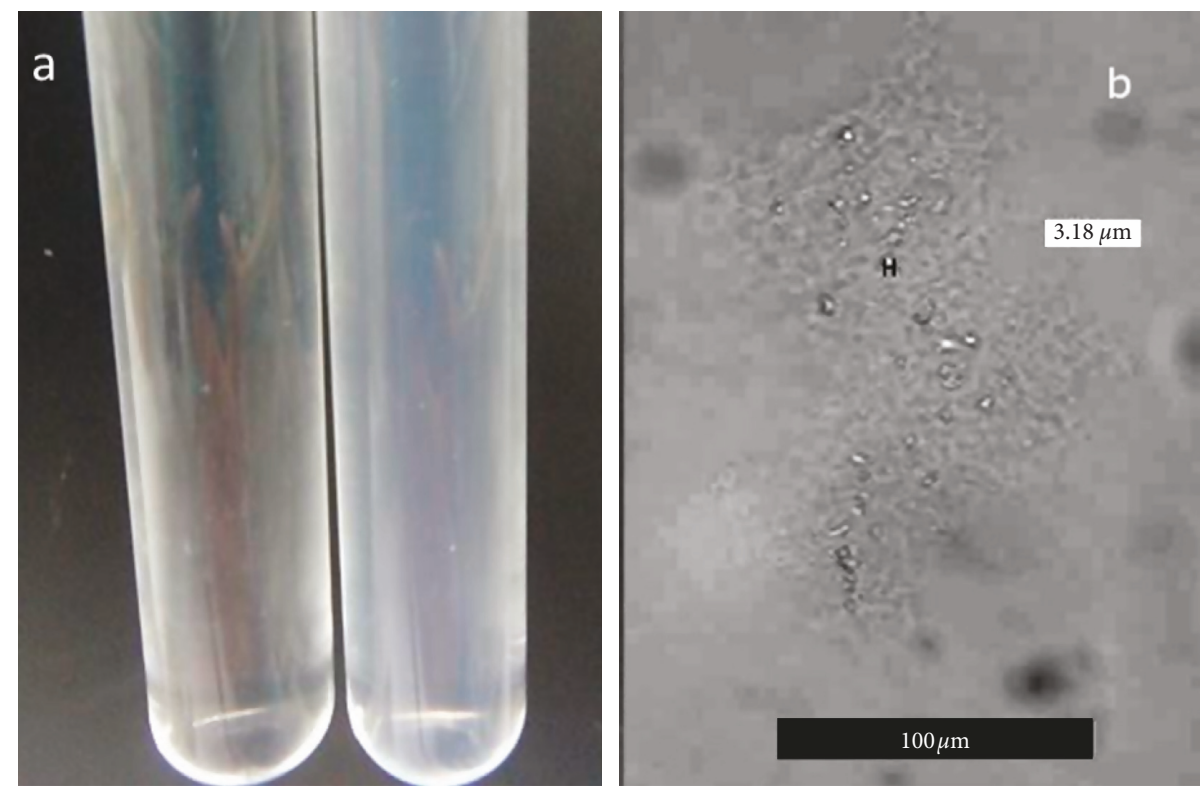

FIgure 1: Hydrogels obtained by adding (a) CS onto CMC and (b) CMC onto CS at a ratio of 75/1 (pore size around $3 \mu \mathrm{m}$ ).

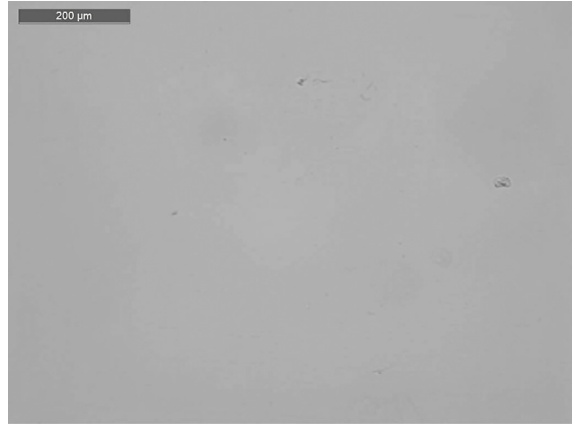

(a)

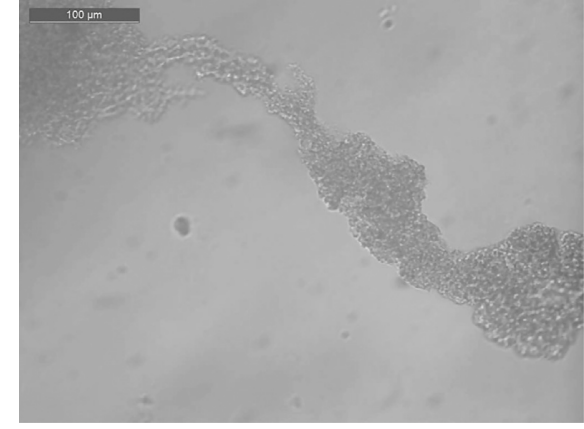

(b)

Figure 2: Micrographs of hydrogels obtained by adding (a) CS/CMC at a ratio of 75/1 and (b) CMC/CS for a ratio of 75/1.

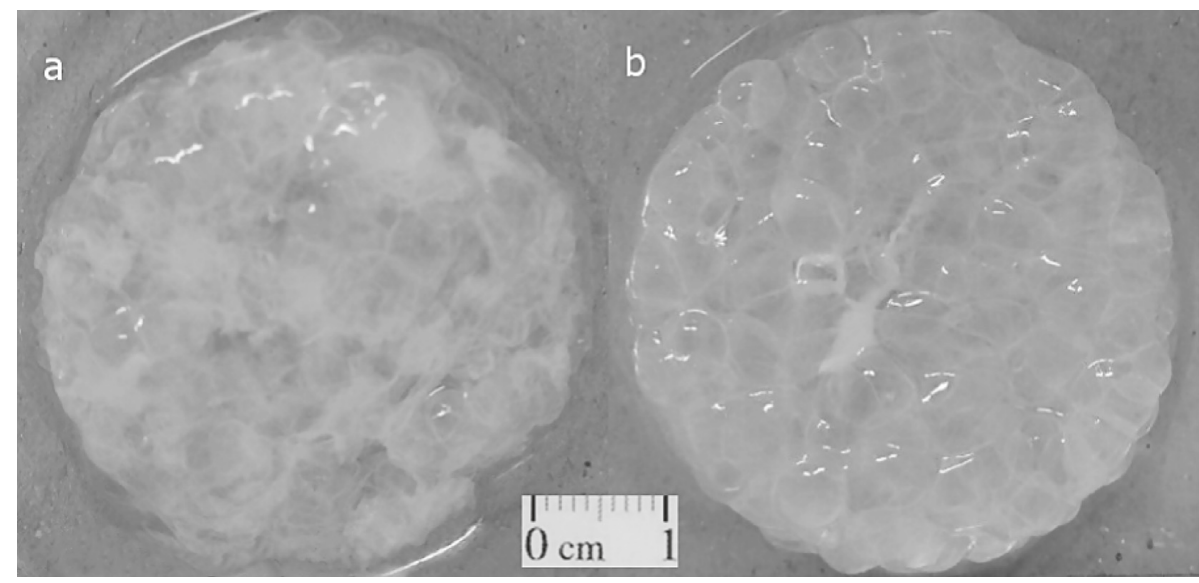

Figure 3: Sponges obtained by adding (a) CMC/CS at a ratio of 1 and (b) CS/CMC for a ratio of 1.

thus forming a core of AA covered by the CS. It was observed that increasing the alginate concentration improved the yield of the gel. Likewise, with an increase in the amount of
AA, the $\mathrm{pH}$ of the gel also increased [23]. Generally speaking, at a basic $\mathrm{pH}, \mathrm{CMC}$ chains adopt a linear chain configuration and shrink as the $\mathrm{pH}$ decreases. AA may 
TABLE 2: The yield of hydrogels at varying ratios of anionic and cationic polymers.

\begin{tabular}{lccc}
\hline Polymers & Ratio & Yield (\%) & Deviation (\%) \\
\hline & 200 & 21.70 & 0.26 \\
& 75 & 11.56 & 0.6 \\
CMC/CS & 32 & 20.10 & 0.97 \\
& 21 & 21.06 & 0.69 \\
& 2.7 & 94.08 & 2.69 \\
\hline AA/CS & 50 & 29.45 & 1.26 \\
& 28 & 12.50 & 0.88 \\
& 12 & 8.30 & 0.56 \\
& 5 & 8.51 & 0.00 \\
CMS/CS & 4 & 10.57 & 0.33 \\
& 320 & 72.56 & 1.43 \\
& 240 & 78.76 & 1.78 \\
& 64 & 52.84 & 2.49 \\
& 60 & 49.96 & 1.09 \\
\end{tabular}

exhibit a loop formation at a $\mathrm{pH}$ around 3, and the CMS is in a state of pregel [24]. Therefore, in the case of CMC/CS, the yield of the gel improved as the $\mathrm{pH}$ decreased. The yield effect was probably due to a tighter structure of the CMC, which in turn could be more easily coated by the CS. These results are in agreement with those reported elsewhere [25].

The initial $\mathrm{pH}$ to polymer solutions were CMC 6.31, CMS 6.61, AA 7.76, CS 2.28, and the different interactions changed the $\mathrm{pH}$ between 2.6 and 3.8 for $\mathrm{CMC} / \mathrm{CS}, 2.95$ and 3.55 for CMS/CS, and 2.65 and 3.05 for AA/CS.

\subsection{Effect of Polymer-Polymer Ratio on Hydrogel Morphology.} $\mathrm{CMC} / \mathrm{CS}$ hydrogels produced cloudy suspensions at higher ratios (ratio > 200), which did not precipitate quickly, whilst an agglomerated hydrogel was observed when the CMC/CS ratio decreased until a maximum agglomeration at a value ratio of 21 .

Gels prepared from CMS also showed changes in appearance, in relation to the order of addition and polymer ratios. Hydrogels at the highest CMS/CS ratio (320) formed a viscous suspension; when the fraction of CMS was reduced, a cloudy suspension was produced. The increase in viscosity is due to a large amount of polymer in the suspension, which prevents the CS from dispersing quickly into the CMS; then by reducing the CMS/CS ratio, the viscosity of the mix is reduced, and CS can interact more easily with the polyanion. Since CMS is a pregel in the form of particles, a lower concentration favors the CMS-CS hydrogen interactions because there are no the impediments for hydrogen bonds to be created between the same starch chains due to the minor amounts of $\mathrm{COO}^{-}$that are dissociated at lower $\mathrm{pH}[23,26]$. The decrease in viscosity is a demonstration that intermolecular complexation between starch chains does not occur at these conditions [27]. It might be assumed that, at the beginning of the addition, the CMS-COOH groups at the surface of the starch granules inside the aggregates formed strong hydrogen bonds that prevent interaction between starch chains [28].
On the contrary, for all the AA/CS ratios, cloudy suspensions were obtained. Other ratios outside the range not reported here also produced precipitates.

According to Devi et al. 2012, the optimal ratio is achieved when the supernatant has a lower viscosity [18]. For this reason, an insoluble complex is formed when the polyanion concentration decreased. Schatz et al. proposed that hydrogel formation leads to flocculation only at balanced charge ratios; however, if interaction may occur well at other ratios [29], it would prevent diffusion and good contact between polymer molecules.

3.4. Morphological Gel Characterization. Figure 4 shows an increase in the agglomeration of particles for CMC/CS hydrogels when the ratio decreased. Lower ratios gave a more structured hydrogel network with apparent longer segments.

Porous sponges were obtained when samples of $\mathrm{CMC} /$ CS hydrogels were freeze-dried. The SEM micrograph at a ratio of 200 (Figure 5(a)) shows a sponge with smaller pores than those exhibited when the ratio equals 75 (Figure 5(b)).

Devi et al. reported that the nature of gel formation for CMC/CS complexes depended on the relative quantity of CS until reaching a point where the interaction improved, leading to an increase in gel yield [18]. Thus, the rise in the agglomeration could be related to a higher interaction between the polymers.

A micrograph of a CMS/CS hydrogel sample (Figure 6) revealed oval particles similar to starch grains. When the polymer-polymer ratio decreased, the hydrogels exhibited a less dispersion of the particles.

The CMS/CS hydrogel is the only one that remained in powder form after freeze-drying. SEM micrographs (Figure 7) confirmed the presence of oval particles like those reported by Assaad et al. [30].

AA/CS formed hydrogels that looked like an agglomerated network (Figure 8), similar to what was reported elsewhere [31]. Few particles lower than $10 \mu \mathrm{m}$ could also be 


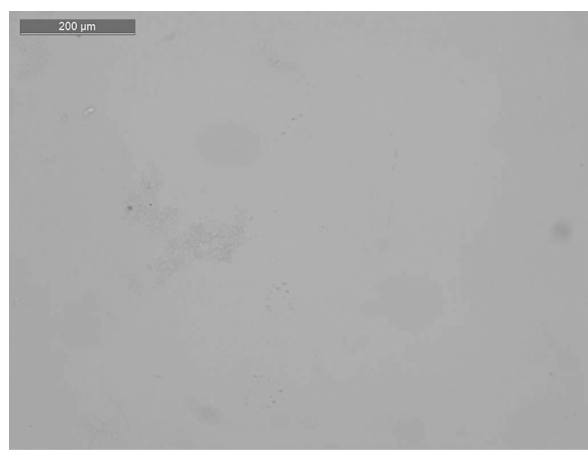

(a)

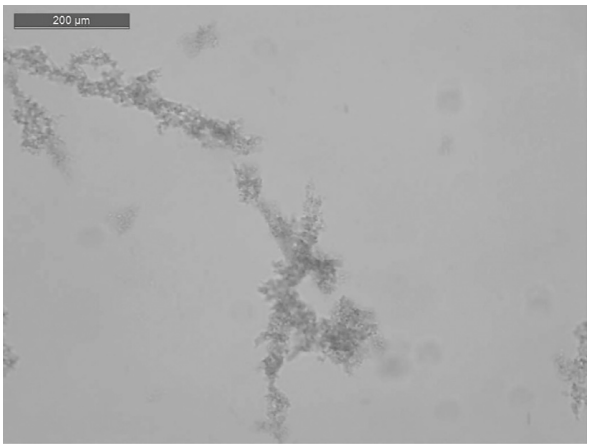

(b)

Figure 4: Microscopy images of CMC/CS hydrogel at ratios: (a) 200 and (b) 32.
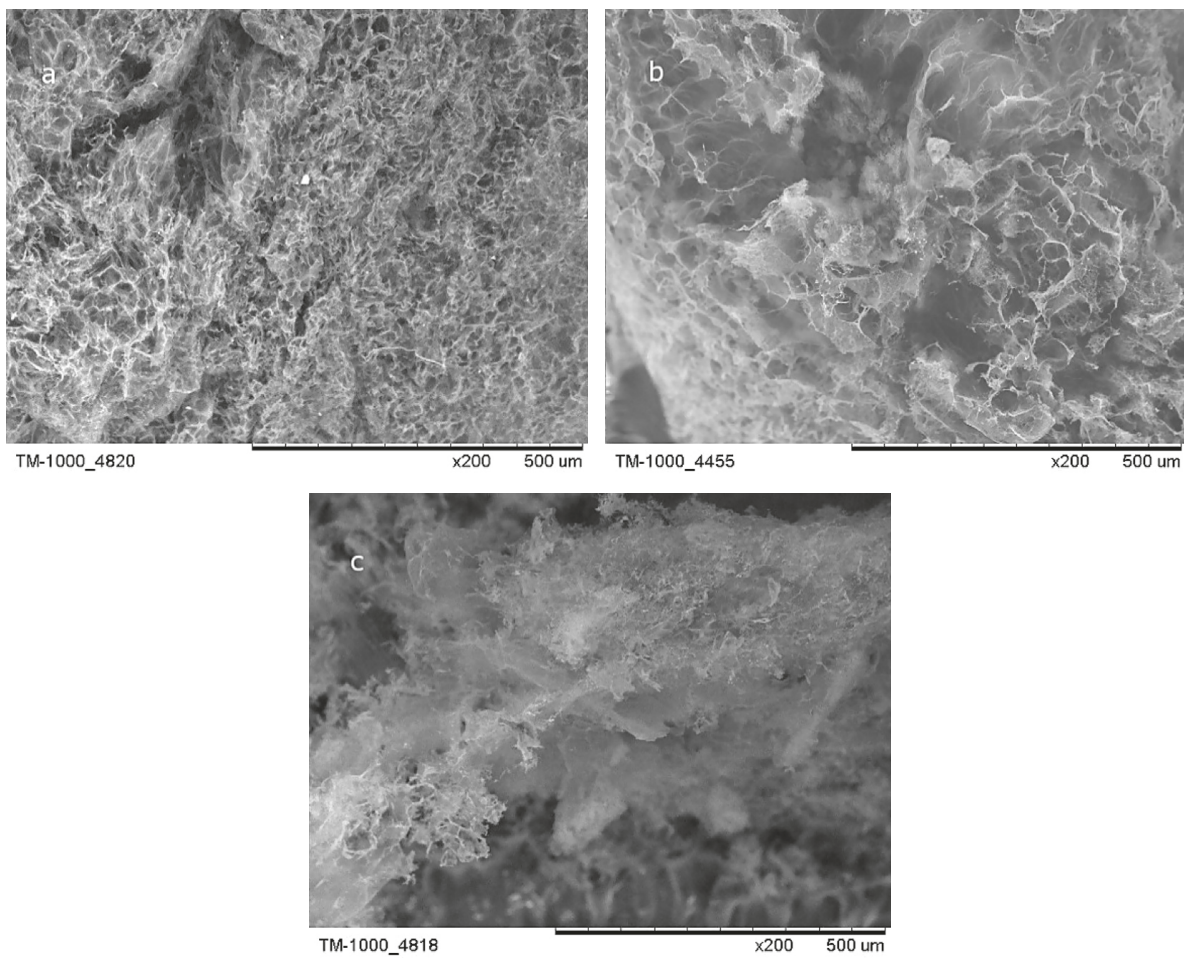

FIGURE 5: SEM images of CMC/CS hydrogel at different ratios: (a) 200, (b) 75, and (c) 32.

observed. At this scale, morphological differences are not very noticeable between different polymer-polymer ratios.

The effect of the AA/CS ratio on hydrogel morphology could be observed under SEM microscopy (Figure 9). The mixture of alginic acid as polyanion and chitosan as polycation produced a three-dimensional crosslinked hydrogel with diverse porous structure; the gels were more homogeneous at lower ratios. This fact was also reported by Baysal et al., who observed that a similar polyelectrolyte complex led to a fibrous and porous hydrogel [32].

In all ratios studied for each polymer combination, a hydrogel was formed. It suggests that an effective interaction occurred between functional groups of polyanions and chitosan [19], making clear that the morphology of hydrogels depended on the preparation conditions [15].
3.5. $\mathrm{pH}$ and Zeta Potential. Table 3 reports the $\mathrm{pH}$ of the polymer solutions before complexation. The $\mathrm{pH}$ of the suspension changed with the polymer-polymer ratio, and some studies reported elsewhere have experimented controlling the $\mathrm{pH}$ with buffers, acids, or bases $[14,18]$. In this work, the $\mathrm{pH}$ of the suspensions was low at lower ratios of the anionic polymer but increased at higher ratios [19]. The greater $\mathrm{pH}$ change was obtained for CMC/CS hydrogels (Figure 10).

The acidic $\mathrm{pH}$ in the polyelectrolyte complex is due to the presence of $\mathrm{H}^{+}$ions (protonation) partially released by the acetic acid in which chitosan was solubilized, which also contributed to an increase in the conductivity. At acidic $\mathrm{pH}$ values, lower than 4-5, carboxyl groups are in the protonated form, which allows the formation of intermolecular 

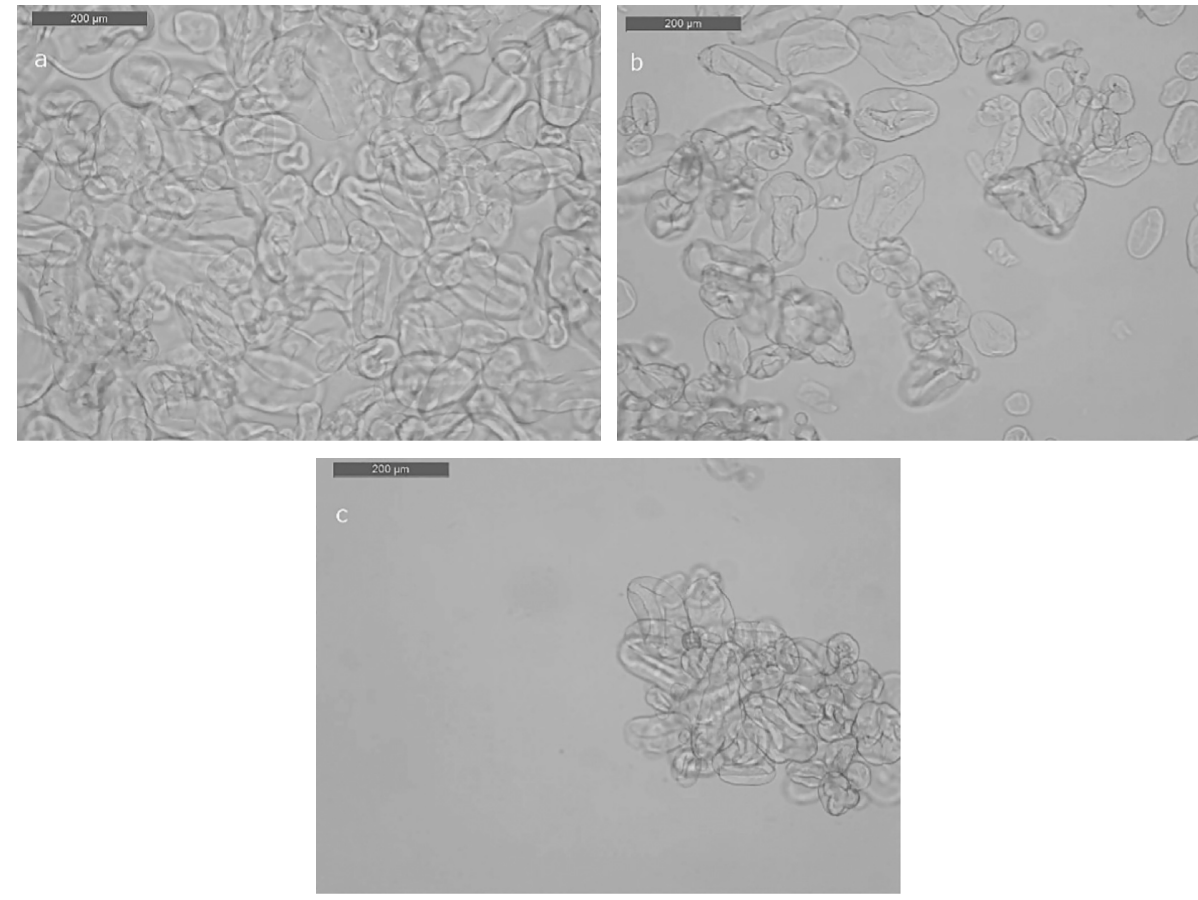

Figure 6: Morphology of CMS/CS hydrogel at ratios of: (a) 320, (b) 64, and (c) 50.
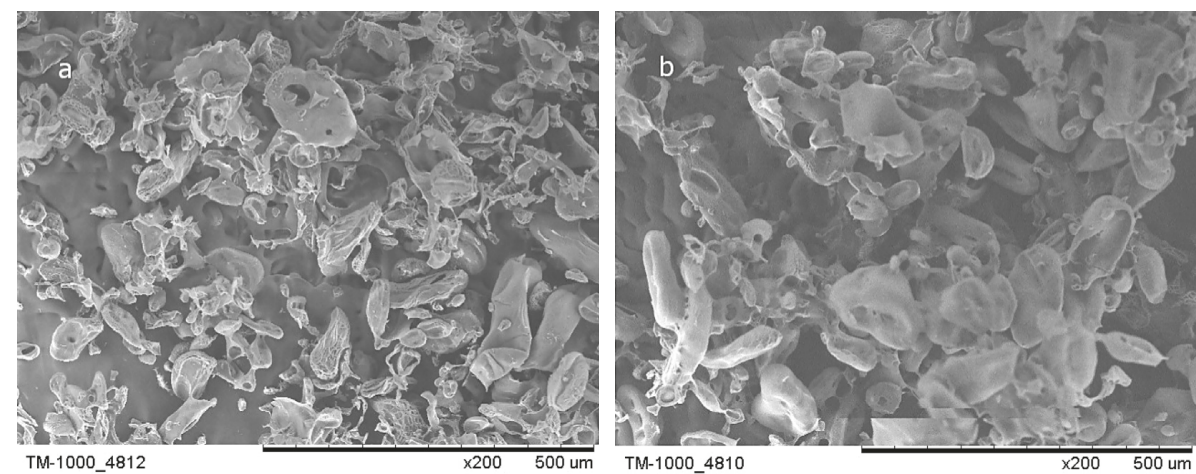

Figure 7: SEM images for CMS/CS hydrogel at different ratios: (a) 320 and (b) 50.

hydrogen bonds between carboxyl groups of the polyanions and chitosan hydroxyl groups [33]. Therefore, the increase or decrease on hydrogel agglomeration for each combination of polymers used in the work that was mentioned before can be explained by the formation or absence of hydrogen bonds (Figure 10).

Another reason for the agglomeration is the unbalanced $\mathrm{COO}^{-} / \mathrm{N}$ ratio in the solutions [19]. Near to the transition from positive to a negative charge (near to neutrality), the aggregation of particles was observed.

Figure 11 shows the effect of the polymer-polymer ratio on the zeta potential of the final solution. The solution charge $(\mathrm{mV})$ has a monotonic tendency to decrease as the polymer-polymer ratio increases, probably due to an increment of negative ions from the polyanions [19].

A high CMC/CS ratio (i.e., 200) resulted in a cloudy suspension with negative zeta potentials $(-962 \mathrm{mV})$. Sæther et al. indicated that working with an excess of the major component stabilizes the particles and no aggregation is obtained [19]. For zeta potentials between $-372 \mathrm{mV}$ and $700 \mathrm{mV}$, the hydrogel tended to flocculate. An abrupt change from negative to a positive charge is also observed. Although the zeta potential of AA/CS systems was negative, the interaction between polymers produced a gel.

On the contrary, regarding the CMS/CS hydrogels, flocculation was stronger at lower ratios (i.e., positive zeta potential). However, no turbidity was observed at $+850 \mathrm{mV}$. Micrographs of individual particles are shown in Figure 12.

With an excess of one of the polymers, the zeta potential had a large positive or negative value. Nonaggregating particles were formed due to an excess of polyanion, which stabilized the hydrogel and prevented the agglomeration [19]. In each case, higher polyanion concentrations did not produce aggregation. This may be due to adsorption of excess polyanion, imparting a negative gel surface charge that would prevent agglomeration. 


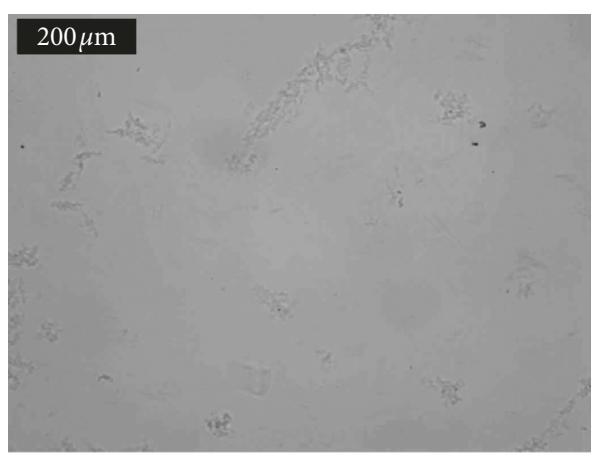

(a)

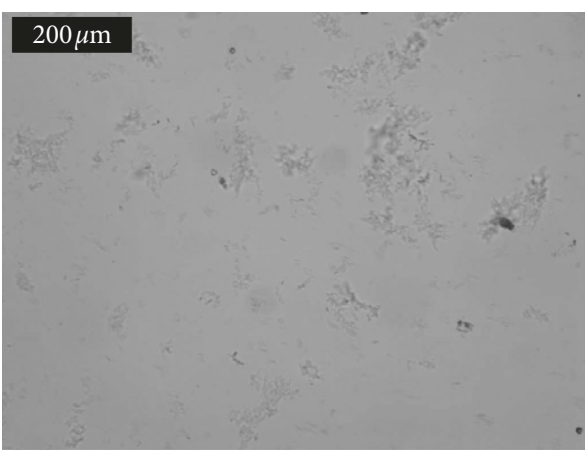

(b)

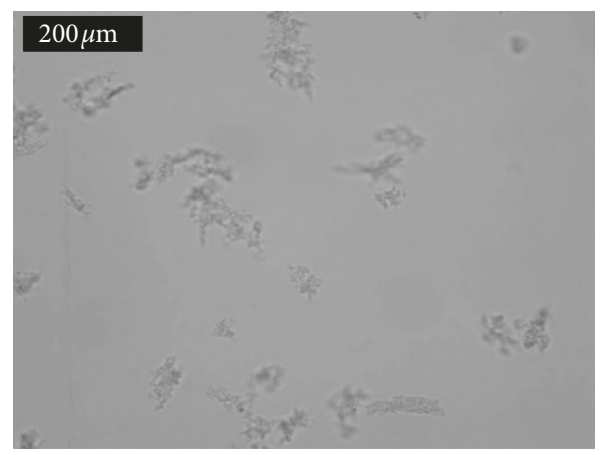

(c)

Figure 8: Morphology of the AA/CS hydrogel at ratios: (a) 50, (b) 12, and (c) 5.
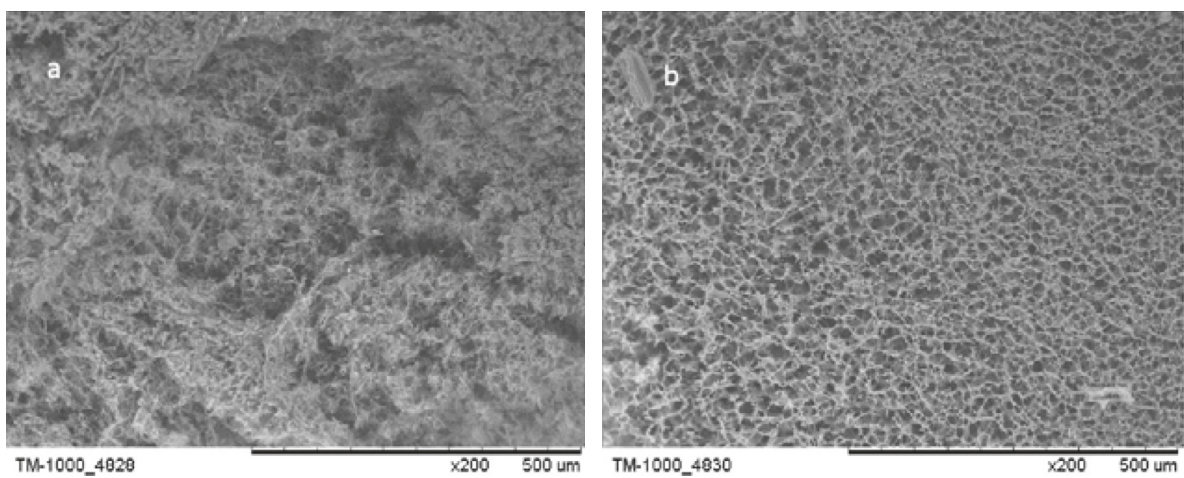

Figure 9: SEM images for AA/CS hydrogel at ratios: (a) 50 and (b) 5.

3.6. FTIR Characterization of Gels. Figures 13-15 show the IR spectra of CS, CMC, CMS, and AA and polyelectrolyte complex of CMC/CS, CMS/CS, and AA/CS.

The spectrum of chitosan had the characteristic bands at 1640 and $1560 \mathrm{~cm}^{-1}$ related to the vibration of carbonyl bonds $(\mathrm{C}=\mathrm{O})$ of the secondary amide and protonated amino groups in CS [34, 35] (Figure 13). Bands identified at 1420 and $1380 \mathrm{~cm}^{-1}$ belonged to methylene and amide II [36] groups bending, respectively. The band at $1310 \mathrm{~cm}^{-1}$ corresponded to $-\mathrm{CH}_{3}$ stretch in acetyl groups, while the band at $1260 \mathrm{~cm}^{-1}$ was related to C-O-H groups [34]. Bands at 1150 , 1070 , and $1030 \mathrm{~cm}^{-1}$ were related to the symmetric and asymmetric stretches of C-O-C bonds [34-36]. The band at $890 \mathrm{~cm}^{-1}$ was attributed to $\mathrm{C}-\mathrm{H}$ wagging of anomeric carbon in the saccharide structure [34].
TABLE 3: $\mathrm{pH}$ of polymers in solution.

\begin{tabular}{ll}
\hline Polymer solution & $\mathrm{pH}$ \\
\hline CMC & 6.31 \\
CMS & 6.61 \\
AA & 7.76 \\
CS & 2.28 \\
\hline
\end{tabular}

The characteristic bands for the CMC are 1590, 1412, $1315,1154,1102,1050$, and $1020 \mathrm{~cm}^{-1}$ (Figure 13). The bands of interest are 1590 and $1412 \mathrm{~cm}^{-1}$, which correspond to asymmetrical and symmetrical stretching of $-\mathrm{COO}^{-}$groups $[36,37]$. The rest of the signals correspond to specific groups of carbohydrates as discussed previously. 


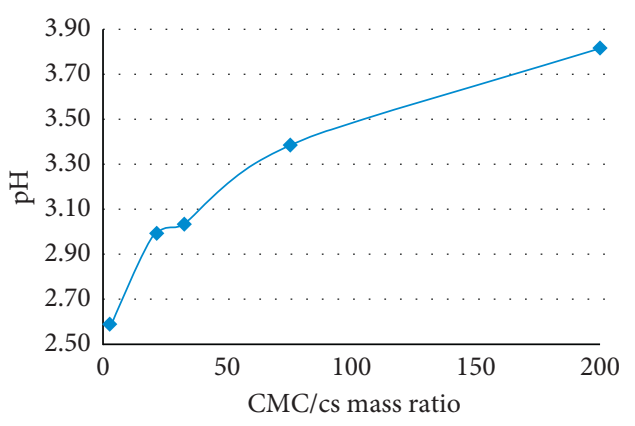

(a)

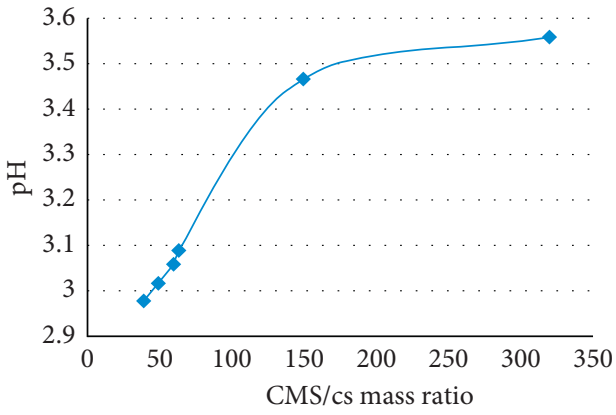

(b)

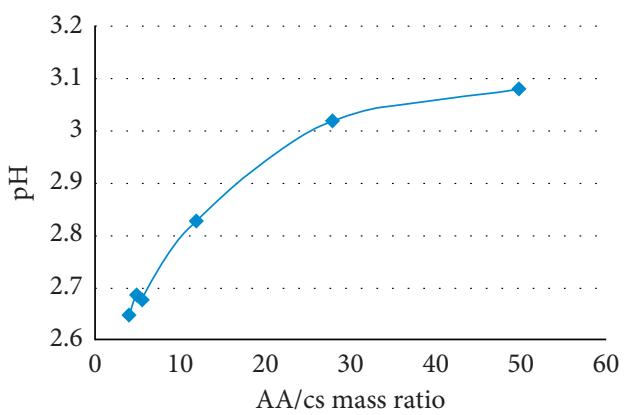

(c)

Figure 10: Effect of polymer-polymer ratio on $\mathrm{pH}$ of the final solution (a) CMC/CS, (b) CMS/CS, and (c) AA/CS.

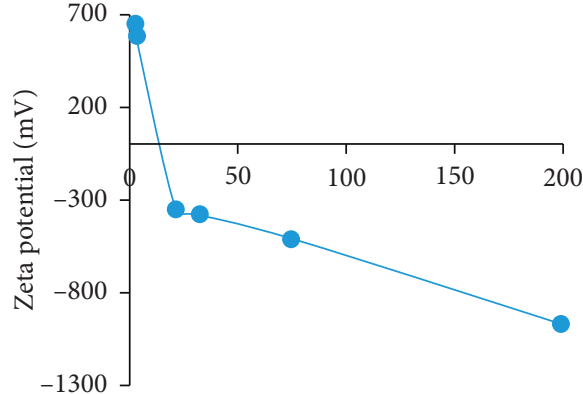

(a)

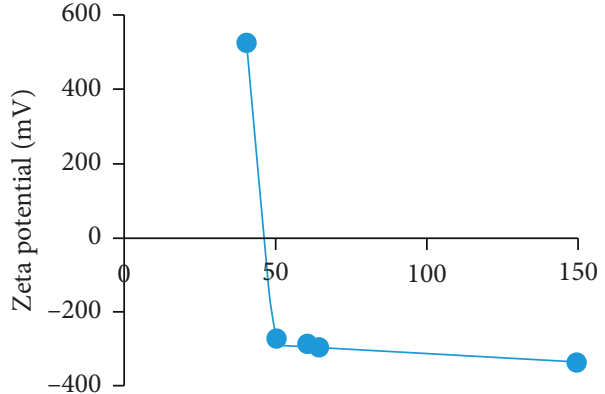

(b)

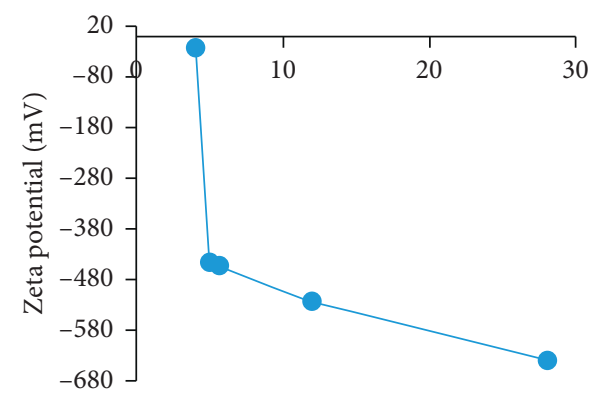

(c)

FIGURE 11: Effect of polymer-polymer ratio on the zeta potential of the final solution (a) CMC/CS, (b) CMS/CS, and (c) AA/CS.

The CMC/CS complex had the characteristic bands of both chitosan and carboxymethylcellulose (Figure 13). The ratio CMC/CS of 200 had all the band characteristics of CMC but also showed the band characteristic of chitosan, i.e., $1380 \mathrm{~cm}^{-1}$; the band at $1060 \mathrm{~cm}^{-1}$ (displacement of
$1070 \mathrm{~cm}^{-1}$ of $\mathrm{CS}$ and $1050 \mathrm{~cm}^{-1}$ of $\mathrm{CMC}$ ) was more pronounced than the band at $1030 \mathrm{~cm}^{-1}$. The ratio CMC/CS of 32 had a new band in $1725 \mathrm{~cm}^{-1}$ that began to show up due to $\mathrm{C}=\mathrm{O}$ stretching [37]. The signal at $1640 \mathrm{~cm}^{-1}$ of the amide in CS diminished greatly due to the greater amount of CMC, 


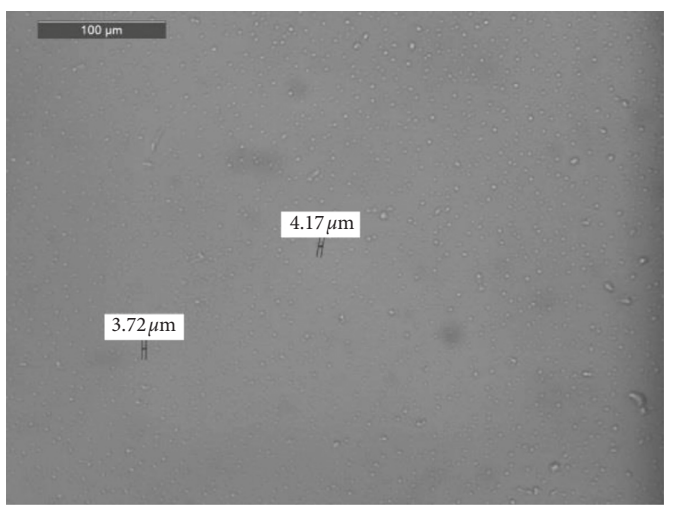

Figure 12: Particles of CMS/CS at ratio 9 (particle size around $4 \mu \mathrm{m})$.

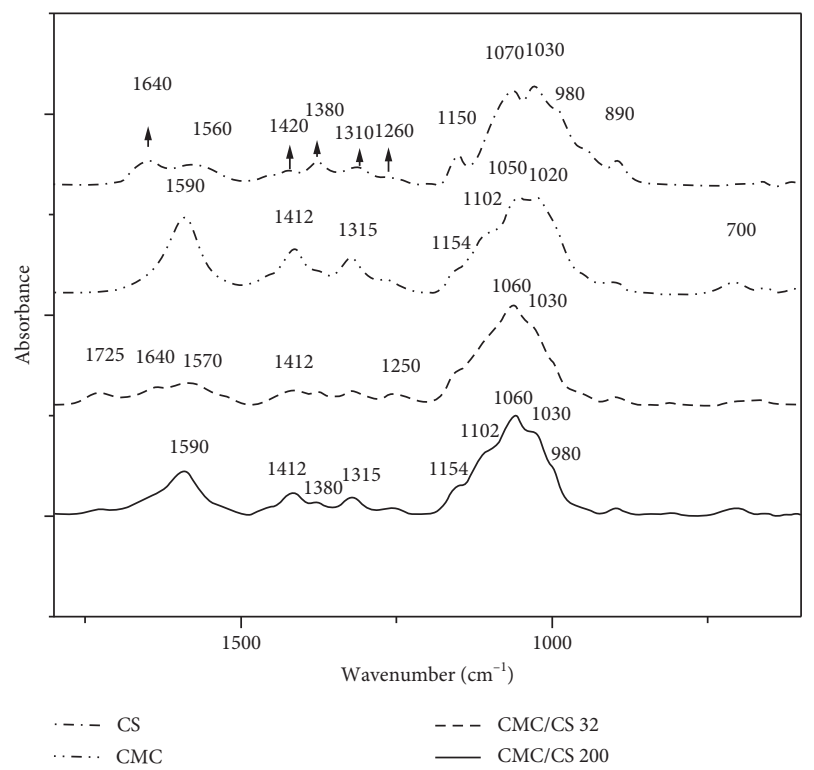

Figure 13: FTIR spectra from CS, CMC, CMC/CS ratio 32, and CMC/CS ratio 200.

and thus the CMC signal at $1590 \mathrm{~cm}^{-1}$ predominating, and it is the characteristic of intermacromolecular complex formation [36]. In the CMC/CS ratio 200, the signal at $1590 \mathrm{~cm}^{-1}\left(-\mathrm{COO}^{-}\right)$is the predominant band. Both bands at 1412 and $1315 \mathrm{~cm}^{-1}$ corresponded to CMC. Signals at $1380 \mathrm{~cm}^{-1}$ corresponding to $-\mathrm{CH}_{2}$ of $\mathrm{CS}$ appeared also as a weak peak in this complex system.

The FTIR spectrum of CMS (Figure 14) has the characteristic carboxylate absorption band at $1570 \mathrm{~cm}^{-1}$ [38]. The $-\mathrm{CH}_{2}$ symmetrical stretch band was found shifted to $1420 \mathrm{~cm}^{-1}$ [39]; previous bands, along with the $1320 \mathrm{~cm}^{-1}$ band, were the characteristics of CMS [40]. In addition, bands occurred at 1150,1080 , and $1000 \mathrm{~cm}^{-1}$, arising from C-O bond stretching vibration [40].

The CMS/CS complex, ratio 320, had more characteristic bands of the carboxymethyl starch than those of chitosan (Figure 14). The spectrum shows the band $1570 \mathrm{~cm}^{-1}$ characteristic of $\mathrm{COO}^{-}$groups of CMS [38].

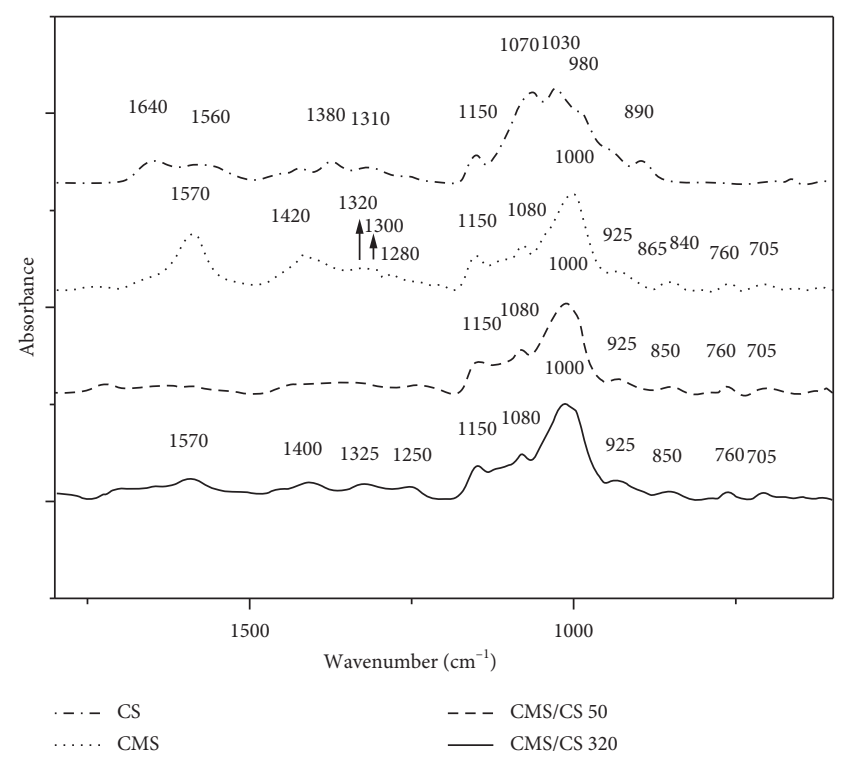

FIgure 14: FTIR spectra from CS, CMS, CMS/CS ratio 50, and CMS/CS ratio 320 .

The biggest difference between the two CMS/CS ratio 50 and CMS/CS ratio 320 complexes was in the wavenumber range $1570-1325 \mathrm{~cm}^{-1}$. The CMS/CS gel at ratio $50 \mathrm{did}$ not show representative bands, while the CMS/CS gel at ratio 320 was more similar to the CMS spectrum, specifically the bands that corresponded to the vibration of carbonyl bonds $\left(\mathrm{COO}^{-}, 1570 \mathrm{~cm}^{-1}\right)$ of the CMS [38].

The AA spectrum (Figure 15) shows an important band at $1600 \mathrm{~cm}^{-1}$ due to $\mathrm{C}=\mathrm{O}$ stretch of the acid group [35, 41]. Furthermore, it presented a band at $1400 \mathrm{~cm}^{-1}$ probably due to $\mathrm{C}-\mathrm{OH}$ deformation vibrations with the contribution of $\mathrm{O}-\mathrm{C}-\mathrm{O}$ symmetric stretching vibration of the carboxylate group [41]. Between 1290 and $1080 \mathrm{~cm}^{-1}$ appeared bands of $\mathrm{C}-\mathrm{O}$ assigned to $\mathrm{C}-\mathrm{C}-\mathrm{H}$ and $\mathrm{O}-\mathrm{C}-\mathrm{H}$ deformation, $\mathrm{C}-\mathrm{O}$ stretching, and C-O and C-C stretching. At $1020 \mathrm{~cm}^{-1}$, there was the characteristic absorption band of $\mathrm{C}-\mathrm{O}$ stretching [35, 41]. The bands at 940 and $880 \mathrm{~cm}^{-1}$ were assigned to $\mathrm{C}-\mathrm{O}$ of uronic acids and to $\mathrm{C} 1-\mathrm{H}$ deformation of $\beta$-mannuronic acid units, respectively. The band at $820 \mathrm{~cm}^{-1}$ possibly belonged to mannuronic residues [41].

The AA/CS complexes at a ratio of 5 and 50 had characteristic bands more related to AA than CS (Figure 15). The spectrum of the gel at ratio 5 had a band at $1730 \mathrm{~cm}^{-1}$ due to $\mathrm{C}=\mathrm{O}$ stretch. The band at $1600 \mathrm{~cm}^{-1}$ appeared in both complexes, but more accentuated in AA/CS ratio 5. It was also noticed a shoulder at $1530 \mathrm{~cm}^{-1}$ probably due to N-H from CS. However, the signal at 1080 in AA/CS ratio 50 was better defined than in the gel at ratio 5. Also, the band at $1020 \mathrm{~cm}^{-1}$ appeared to be wider than the same band in AA. The band at $1150 \mathrm{~cm}^{-1}$ resembled more likely the one in CS.

Higher polymeric ratios decreased the agglomeration for hydrogels of the types CMC/CS and CMS/CS, while the hydrogel of AA/CS was porous and more homogeneous at smaller ratios. Agglomerated hydrogels (lower ratios) exhibited greater zeta potential values and smaller pHs. 


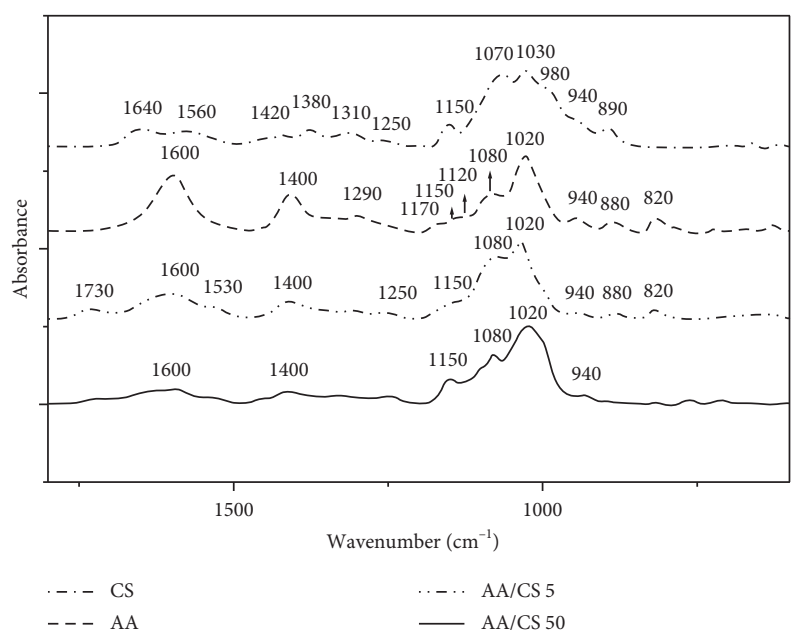

FIgURE 15: FTIR spectra from CS, AA, AA/CS ratio 5, and AA/CS ratio 50.

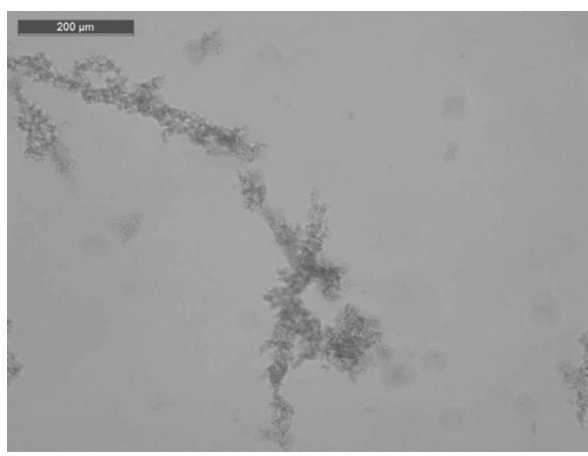

(a)

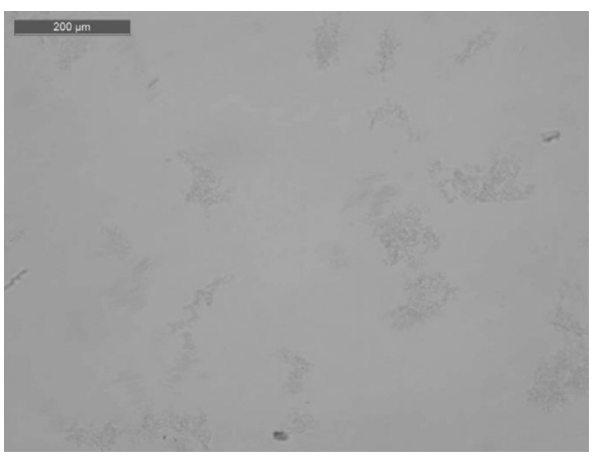

(b)

FIGURE 16: Hydrogels for CMC/CS 32: (a) after the hydrogel formation and (b) after 24 hours of hydrogel formation.
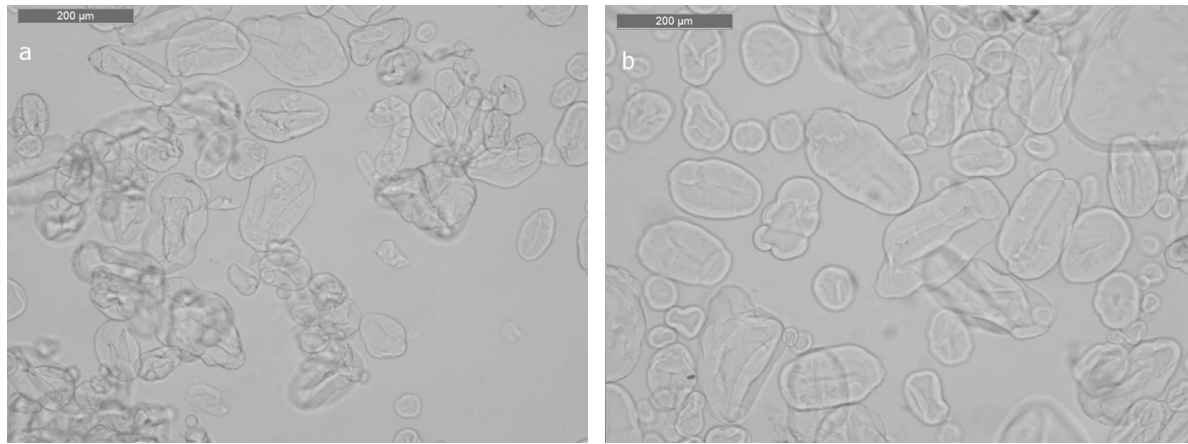

FIgURE 17: Hydrogels for CMS/CS 64: (a) after of gelation time and (b) before of gelation time.

3.7. Effect of Cure Time on Hydrogel Morphology. A more agglomerated hydrogel was obtained 12 hours after mixing for gelation. An extended aging time increases the apparent degree of crosslinking because more acid groups of CMC can react with amino groups of CS [42]. This process was accompanied by a decrease in the zeta potential of the system. CMC/CS hydrogel at ratio 32 had a charge of $-276 \mathrm{mV}$ before the gelation time, changing to $-372 \mathrm{mV}$ after gelling (Figure 16).
The CMS/CS had the same behavior as CMC/CS complexes. Before gelation time, CMS/CS at ratio 64 had a charge of $-25 \mathrm{mV}$, while the gel with cure time had a potential of $-293 \mathrm{mV}$ (Figure 17).

Differences occurred with AA/CS at a ratio of 5 (alginic acid $0.28 \% \mathrm{w} / \mathrm{v}$ ), which had a potential of $-476 \mathrm{mV}$ before gelation, keeping approximately the same z-potential after the gelation time $(-444 \mathrm{mV})$. Also, there were no major changes in the morphology of the gel, except that more 


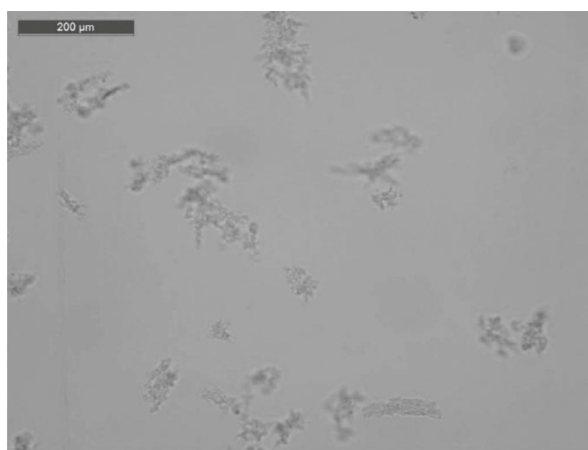

(a)

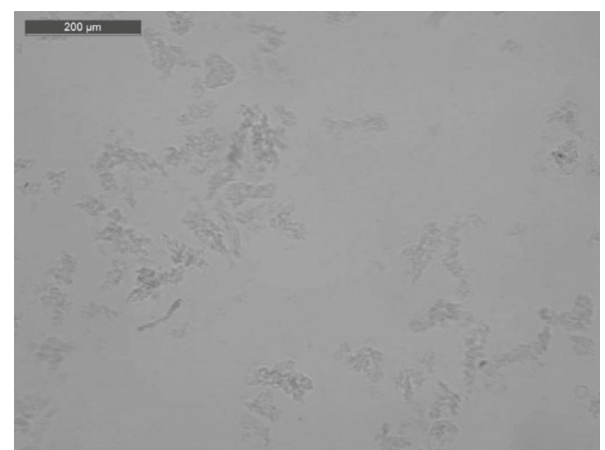

(b)

FIgURE 18: Hydrogels for AA/CS 5: (a) after of gelation time and (b) before of gelation time.

swelling occurred as the gelation time was reached (Figure 18).

\section{Conclusions}

The main objective of this work was to determine the effect of the polymer-polymer ratio and the order of addition on the morphology of hydrogels that could be promising materials for drug encapsulation. It can be concluded that the sequence of addition of polymer had indeed an effect on hydrogel formation, causing more aggregates by dropping the anionic polymer over the cationic polymer at lower concentrations.

The polymer-polymer ratio had a great influence on hydrogel morphology of CMC/CS, CMS/CS, and AA/CS. Higher polymeric ratios decreased the agglomeration for hydrogels of the type CMC/CS and CMS/CS, while the hydrogel of AA/CS was porous and more homogeneous at lower ratios. Agglomerated hydrogels at lower ratios exhibited greater zeta potential values and lower $\mathrm{pH}$ values.

\section{Data Availability}

The data used to support the findings of this study are available from the corresponding author upon request.

\section{Conflicts of Interest}

The authors declare that there are no conflicts of interest in the publication of these results.

\section{Acknowledgments}

The authors are grateful to the Alianza del Pacifico México for the financial support of the research stay at the Departamento de Madera, Celulosa y Papel of the Universidad de Guadalajara. The authors also acknowledge the support provided by Colciencias for financing the researcher and CIDI (UPB) for the financial support through internal project.

\section{References}

[1] G. Milcovich, S. Lettieri, F. E. Antunes et al., "Recent advances in smart biotechnology: hydrogels and nanocarriers for tailored bioactive molecules depot," Advances in Colloid and Interface Science, vol. 249, pp. 163-180, 2017.

[2] X. Guan, M. Avci-Adali, E. Alarcin et al., "Development of hydrogels for regenerative engineering," Biotechnology Journal, vol. 12, no. 5, article 1600394, 2017.

[3] J. Siepmann, R. A. Siegel, and M. J. Rathbone, Fundamentals and Applications of Controlled Release Drug Delivery, Springer, Berlin, Germany, 2012.

[4] R. Barbucci, Hydrogels: Biological Properties and Applications, Springer, Berlin, Germany, 2009.

[5] R. M. Ottenbrite, K. Park, and T. Okano, Biomedical Applications of Hydrogels Handbook, Springer, New York, NY, USA, 2010.

[6] P. Patil, C. Daksha, and M. Wagh, "A review on ionotropic gelation method: novel approach for controlled gastroretentive gelispheres," International Journal of Pharmacy and Pharmaceutical Sciences, vol. 4, no. 4, pp. 27-32, 2012.

[7] R. V. Kulkarni, R. Boppana, G. Krishna Mohan, S. Mutalik, and N. V. Kalyane, "pH-responsive interpenetrating network hydrogel beads of poly(acrylamide)- $g$-carrageenan and sodium alginate for intestinal targeted drug delivery: synthesis, in vitro and in vivo evaluation," Journal of Colloid and Interface Science, vol. 367, no. 1, pp. 509-517, 2012.

[8] A. S. Hoffman, "Hydrogels for biomedical applications," Advanced Drug Delivery Reviews, vol. 54, no. 1, pp. 3-12, 2002.

[9] Z. Liu, Y. Jiao, Y. Wang, C. Zhou, and Z. Zhang, "Polysaccharides-based nanoparticles as drug delivery systems," Advanced Drug Delivery Reviews, vol. 60, no. 15, pp. 1650-1662, 2008.

[10] C. Alvarez-Lorenzo, B. Blanco-Fernandez, A. M. Puga, and A. Concheiro, "Crosslinked ionic polysaccharides for stimulisensitive drug delivery," Advanced Drug Delivery Reviews, vol. 65, no. 9, pp. 1148-1171, 2013.

[11] J. Panyam and V. Labhasetwar, "Biodegradable nanoparticles for drug and gene delivery to cells and tissue," Advanced Drug Delivery Reviews, vol. 55, no. 3, pp. 329-347, 2003.

[12] K. S. Soppimath, T. M. Aminabhavi, A. R. Kulkarni, and W. E. Rudzinski, "Biodegradable polymeric nanoparticles as drug delivery devices," Journal of Controlled Release, vol. 70, no. 1-2, pp. 1-20, 2001.

[13] V. R. Sinha, A. K. Singla, S. Wadhawan et al., "Chitosan microspheres as a potential carrier for drugs," International Journal of Pharmaceutics, vol. 274, no. 1-2, pp. 1-33, 2004.

[14] H. Fukuda, "Polyelectrolyte complexes of chitosan with sodium carboxymethylcellulose," Bulletin of the Chemical Society of Japan, vol. 53, no. 4, pp. 837-840, 1980.

[15] I. M. El-Sherbiny, M. Abdel-Mogib, A.-A. M. Dawidar, A. Elsayed, and H. D. C. Smyth, "Biodegradable pH-responsive 
alginate-poly (lactic-co-glycolic acid) nano/micro hydrogel matrices for oral delivery of silymarin," Carbohydrate Polymers, vol. 83, no. 3, pp. 1345-1354, 2011.

[16] J. S. Patil, M. V. Kamalapur, S. C. Marapur, and D. V. Kadam, "Ionotropic gelation and polyelectrolyte complexation: the novel techniques to design hydrogel particulate sustained, modulated drug delivery system: a review," Digest Journal of Nanomaterials and Biostructures, vol. 5, no. 1, pp. 241-248, 2010.

[17] S. Banerjee, L. Siddiqui, S. S. Bhattacharya et al., "Interpenetrating polymer network (IPN) hydrogel microspheres for oral controlled release application," International Journal of Biological Macromolecules, vol. 50, no. 1, pp. 198-206, 2012.

[18] N. Devi, D. K. Kakati, and T. K. Maji, "Development of polyelectrolyte complex microparticles for the encapsulation of isoniazid," Macromolecular Symposia, vol. 313-314, no. 1, pp. 69-78, 2012.

[19] H. V. Sæther, H. K. Holme, G. Maurstad, O. Smidsrød, and B. T. Stokke, "Polyelectrolyte complex formation using alginate and chitosan," Carbohydrate Polymers, vol. 74, no. 4, pp. 813-821, 2008.

[20] R. Barbucci, A. Magnani, and M. Consumi, "Swelling behavior of carboxymethylcellulose hydrogels in relation to cross-linking, $\mathrm{pH}$, and charge density," Macromolecules, vol. 33, no. 20, pp. 7475-7480, 2000.

[21] W. Liu, L. Lv, Y. Li et al., "Effects of slurry composition on the properties of 3-1 type porous PZT ceramics prepared by ionotropic gelation," Ceramics International, vol. 43, no. 8, pp. 6542-6547, 2017.

[22] A. D. Kulkarni, Y. H. Vanjari, K. H. Sancheti et al., "Polyelectrolyte complexes: mechanisms, critical experimental aspects, and applications," Artificial Cells, Nanomedicine, and Biotechnology, vol. 44, no. 7, pp. 1615-1625, 2016.

[23] O. Gåserød, O. Smidsrød, and G. Skjåk-Bræk, "Microcapsules of alginate-chitosan-I: a quantitative study of the interaction between alginate and chitosan," Biomaterials, vol. 19, no. 20, pp. 1815-1825, 1998.

[24] K. Y. Lee, W. H. Park, and W. S. Ha, "Polyelectrolyte complexes of sodium alginate with chitosan or its derivatives for microcapsules," Journal of Applied Polymer Science, vol. 63, no. 4, pp. 425-432, 1997.

[25] H. Fukuda and Y. Kikuchi, "Polyelectrolyte complexes of sodium carboxymethylcellulose with chitosan," Die Makromolekulare Chemie, vol. 180, no. 6, pp. 1631-1633, 1979.

[26] T. T. Khong, O. A. Aarstad, G. Skjåk-Bræk, K. I. Draget, and K. M. Vårum, "Gelling concept combining chitosan and alginate-proof of principle," Biomacromolecules, vol. 14, no. 8, pp. 2765-2771, 2013.

[27] D. Binh, H. Pham Thi Thu, D. Nguyen Ngoc, D. Nguyen Thanh, and D. Nguyen Nguyet, "A study on size effect of carboxymethyl starch nanogel crosslinked by electron beam radiation," Radiation Physics and Chemistry, vol. 81, no. 7, pp. 906-912, 2012.

[28] Ž. Stojanović, K. Jeremic, S. Jovanović, and M. Dieter Lechner, "A comparison of some methods for the determination of the degree of substitution of carboxymethyl starch," StarchStärke, vol. 57, pp. 79-83, 2005.

[29] C. Schatz, A. Domard, C. Viton, C. Pichot, and T. Delair, "Versatile and efficient formation of colloids of biopolymerbased polyelectrolyte complexes," Biomacromolecules, vol. 5, no. 5, pp. 1882-1892, 2004.

[30] E. Assaad, Y. J. Wang, X. X. Zhu, and M. A. Mateescu, "Polyelectrolyte complex of carboxymethyl starch and chitosan as drug carrier for oral administration," Carbohydrate Polymers, vol. 84, no. 4, pp. 1399-1407, 2011.

[31] H.-J. Kim, H.-C. Lee, J.-S. Oh et al., "Polyelectrolyte complex composed of chitosan and sodium alginate for wound dressing application," Journal of Biomaterials Science, Polymer Edition, vol. 10, no. 5, pp. 543-556, 1999.

[32] K. Baysal, A. Z. Aroguz, Z. Adiguzel, and B. M. Baysal, "Chitosan/alginate crosslinked hydrogels: preparation, characterization and application for cell growth purposes," International Journal of Biological Macromolecules, vol. 59, pp. 342-348, 2013.

[33] Y. Qiu and K. Park, "Environment-sensitive hydrogels for drug delivery," Advanced Drug Delivery Reviews, vol. 64, pp. 49-60, 2012.

[34] S. M. L. Silva, C. R. C. Braga, M. V. L. Fook, C. M. O. Raposo, L. H. Carvalho, and E. L. Canedo, "Application of infrared spectroscopy to analysis of chitosan/clay nanocomposites," in Infrared Spectroscopy-Materials Science, Engineering and Technology, p. 524, Intech Brazil, São Paulo, Brazil, 2012.

[35] G. Lawrie, I. Keen, B. Drew et al., "Interactions between alginate and chitosan biopolymers characterized using FTIR and XPS," Biomacromolecules, vol. 8, no. 8, pp. 2533-2541, 2007.

[36] C. Rosca, M. I. Popa, G. Lisa, and G. C. Chitanu, "Interaction of chitosan with natural or synthetic anionic polyelectrolytes. 1. The chitosan-carboxymethylcellulose complex," Carbohydrate Polymers, vol. 62, no. 1, pp. 35-41, 2005.

[37] Q. Zhao, J. Qian, Q. An, C. Gao, Z. Gui, and H. Jin, "Synthesis and characterization of soluble chitosan/sodium carboxymethyl cellulose polyelectrolyte complexes and the pervaporation dehydration of their homogeneous membranes," Journal of Membrane Science, vol. 333, no. 1-2, pp. 68-78, 2009.

[38] K. Wilpiszewska, T. Spychaj, and W. Paździoch, "Carboxymethyl starch/montmorillonite composite microparticles: properties and controlled release of isoproturon," Carbohydrate Polymers, vol. 136, pp. 101-106, 2016.

[39] S. Jahanizadeh, F. Yazdian, A. Marjani, M. Omidi, and H. Rashedi, "Curcumin-loaded chitosan/carboxymethyl starch/ montmorillonite bio-nanocomposite for reduction of dental bacterial biofilm formation," International Journal of Biological Macromolecules, vol. 105, no. 1, pp. 757-763, 2017.

[40] Q. Jiang, W. Gao, X. Li, Z. Liu, L. Huang, and P.-G. Xiao, "Synthesis and properties of carboxymethyl Pueraria thomsonii Benth. starch," Starch-Stärke, vol. 63, no. 11, 2011.

[41] D. Leal, B. Matsuhiro, M. Rossi, and F. Caruso, "FT-IR spectra of alginic acid block fractions in three species of brown seaweeds," Carbohydrate Research, vol. 343, no. 2, pp. 308316,2008

[42] F. Lenzi, A. Sannino, A. Borriello, F. Porro, D. Capitani, and G. Mensitieri, "Probing the degree of crosslinking of a cellulose based superabsorbing hydrogel through traditional and NMR techniques," Polymer, vol. 44, no. 5, pp. 1577-1588, 2003. 


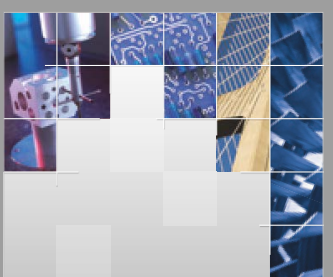

\section{Enfincering}
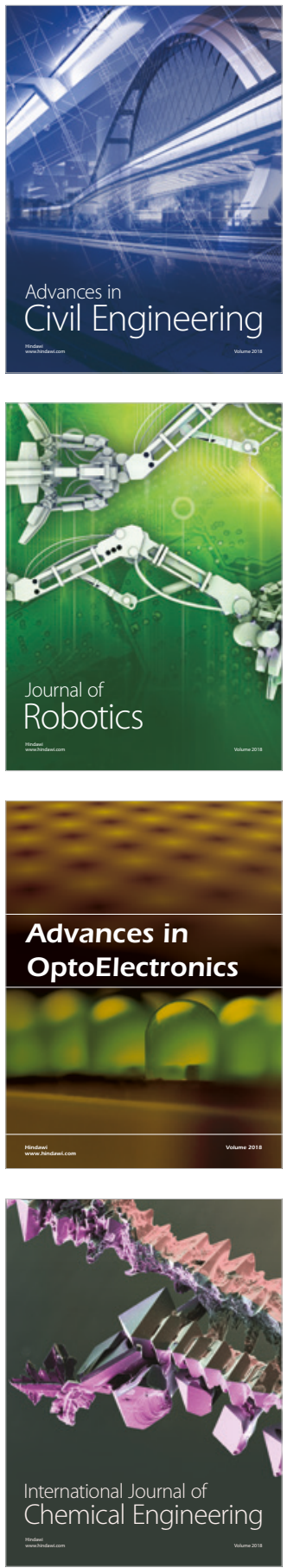

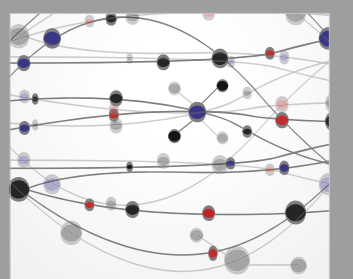

\section{Rotating \\ Machinery}

The Scientific World Journal

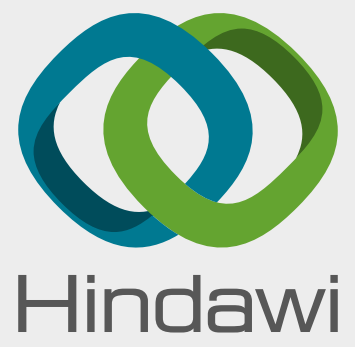

Submit your manuscripts at

www.hindawi.com
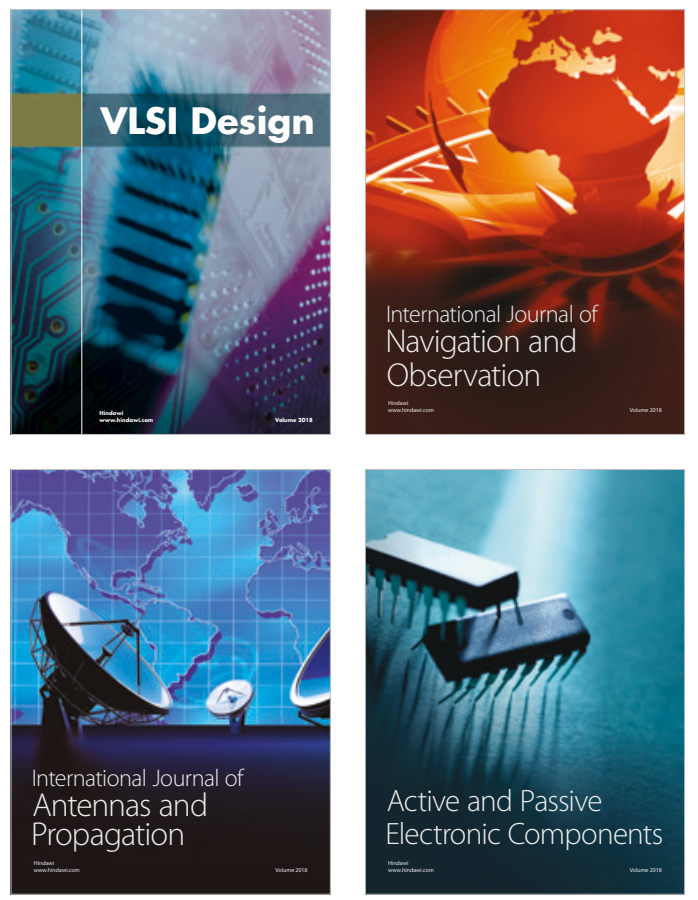
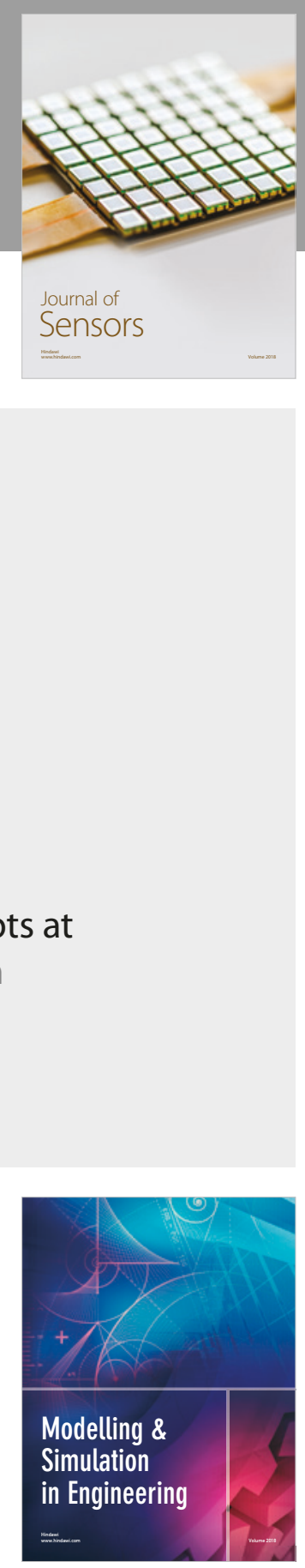

\section{Advances \\ Multimedia}
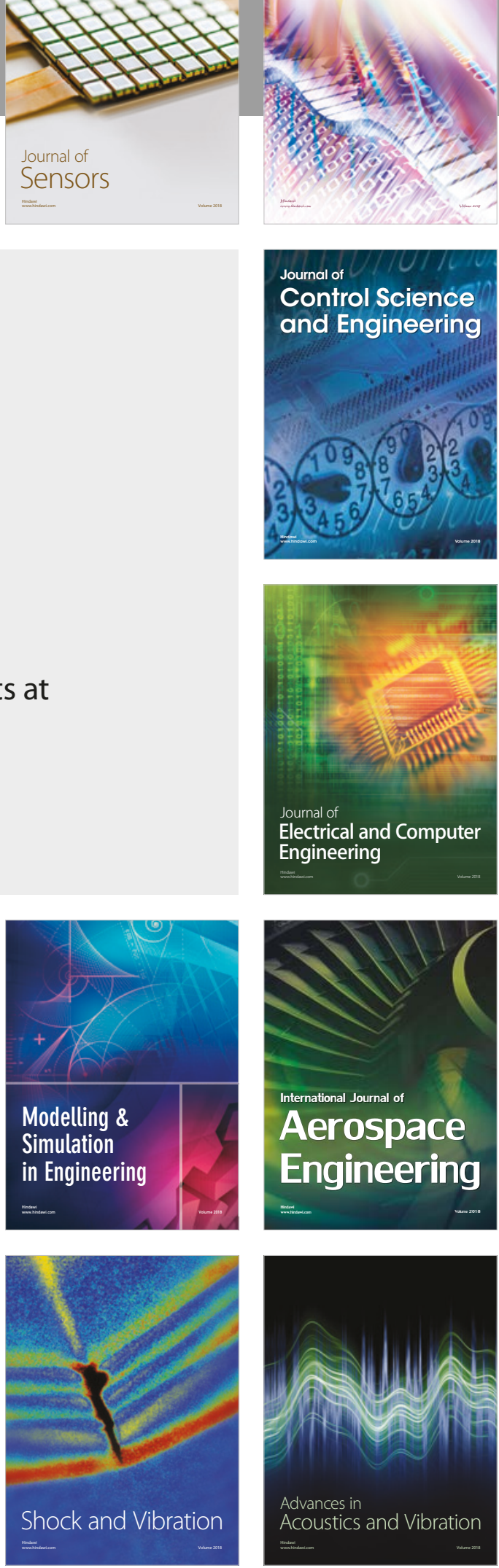